\title{
The Lithiasis of Choledoque: Epidemiological Aspects, Clinics and Therapeutiques in the Surgery Department " $A$ " at the University Hospital Point G
}

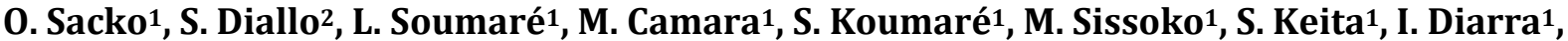 \\ M. Konaté3, M. Traoré4, G. Soumaré5, D. Dakouo'1, M. Coulibaly¹, H. Dicko5, Y. Dianessi' \\ A. Koita ${ }^{1}$, Z. Sanogo ${ }^{1}$
}

${ }^{1}$ Department of Surgery “A”, University Hospital of Point G, Bamako, Mali

${ }^{2}$ Department of Surgery “B”, University Hospital of Point G, Bamako, Mali

${ }^{3}$ Department of Surgery, Reference Center of Town 6, Bamako, Mali

${ }^{4}$ Department of Gynecology-Obstetrics, University Hospital of Point G, Bamako, Mali

${ }^{5}$ Department of Intensive Care, University Hospital of Point G, Bamako, Mali

Email: ousacko72@gmail.com

How to cite this paper: Sacko, O., Diallo, S., Soumaré, L., Camara, M., Koumaré, S., Sissoko, M., Keita, S., Diarra, I., Konaté, M., Traoré, M., Soumaré, G., Dakouo, D., Coulibaly, M., Dicko, H., Dianessi, Y., Koita, A. and Sanogo, Z. (2019) The Lithiasis of Choledoque: Epidemiological Aspects, Clinics and Therapeutiques in the Surgery Department "A" at the University Hospital Point G. Surgical Science, 10, 281-286. https://doi.org/10.4236/ss.2019.108030

Received: July 10, 2019

Accepted: August 11, 2019

Published: August 14, 2019

Copyright $\odot 2019$ by author(s) and Scientific Research Publishing Inc. This work is licensed under the Creative Commons Attribution-NonCommercial International License (CC BY-NC 4.0). http://creativecommons.org/licenses/by-nc/4.0/ c) (i) (8) Open Access

\begin{abstract}
Considered as rare in Africa lithiasis of the main bile duct (MBD) is a potentially serious pathology, diagnosis is facilitated by imaging tests (ultrasound, CT, MRI cholangiopancreatography). Its surgical management is improved by laparoscopy coupled with interventional endoscopy. However, laparotomy remains the only way in Mali. This was a 14-years retrospective and descriptive study (2010-2014). All patients with BPV lithiasis were included. We studied the field, antecedents, clinical, biological, radiological, therapeutic and outcome aspects. 40 cases of stones in the main bile duct were collected during the study period. The hospital frequency was 2.8 cases per year, the clinical signs dominated by the Charcot triad (pain, fever, jaundice) found in 40 cases (100\%). The average age was 60 years, female represented $70 \%$ of cases. Ultrasonography was the most requested review in 40 cases (100\%). The procedure performed was cholecystectomy associated with choledochotomy with calculation extraction in all patients (100\% of cases). One case of biliary fistula and one case of wall abscess were observed. The mortality was $5 \%$ and the simple suited in $90 \%$ of the cases. The lithiasis of the main bile duct is an infrequent pathology in Mali and potentially serious. This diagnosis is assisted in our context by ultrasound and CT. Laparotomy remains the only route of entry in Mali.
\end{abstract}




\section{Keywords}

Lithiasis of the CBD, Surgery, Cholodochotomy

\section{Introduction}

The choledocholithiasis is the presence of one or more stones in the main bile duct [1]. In the literature, the frequency of the lithiasis of the main bile duct oscillates between $2 \%$ and $28 \%$ of biliary lithiasis in general [2]. Biliary stones are considered rare in Africa [3], but are common in Western countries where it affects the adult population in a proportion of $9 \%$ to $12 \%$ in France and 15\% to $20 \%$ in the USA [4].

In Africa: in Niger SANI R. in 2007 found 11\% of the main bile duct stones in the National Hospital of Niamey in 136 cases of cholelithiasis [5]. In Burkina Faso, TRAORE S. S. in 2009 found that the lithiasis of the main bile duct represents $25.6 \%$ of the biliary lithiases in the visceral surgery department of the Yalgado OUEDRAOGO University Hospital Center in Ouagadougou [6]. In Mali the stones in the common bile duct represent $28.57 \%$ of gallstones in the general surgery departments of University Hospital Centers [7]. The exploration of the main bile duct can be done by transcutaneous ultrasonography, retrograde opacification of the main bile duct, echo endoscopy, cholangiography and MRI [8].

The standard treatment of cholelithiasis of the main bile duct was for a long time "traditional" surgery performed by laparotomy. This therapeutic approach was based on a well codified surgical technique with very satisfactory results in terms of mortality, morbidity and residual stones. The combined surgical/endoscopic intraoperative treatment consists of a laparoscopic cholecystectomy, an intraoperative endoscopic sphincterotomy, facilitated by the introduction of a guide wire introduced during the perioperative cholangiography has replaced the laparotomy in the West. The overall mortality is on average $5 \%$ depending on age, defects and especially the severity of complications [9].

Due to the rareness of the publications on the treatment of choledochal lithiasis in Mali, we conducted a study on the management of choledochal lithiasis in Surgery A at the Point G UHC.

\section{Patients and Method}

Type and period of study: This was a retrospective and descriptive study from January 2000 to December 2014 (14 years old) in the surgical unit A of the Point G. UHC.

Framework of study: This work was done in the surgical unit A of the Point G. UHC.

Inclusion criteria: We included patients with the diagnosis of cholelithiasis was laid in pre- and/or during surgery, the patients with cholelithiasis pre and/or 
intraoperatively associated with cholelithiasis or other associated pathologies.

Criteria of non-inclusion: We have not included in this study patients operated for gallstones without stones bile and all patients whose records were unusable.

Diagnosis criteria: the diagnosis of choledochal lithiasis was clinical and paraclinical (ultrasonography and computed tomography).

Sociodemographic data of the patient, the clinical and para clinical parameters, the diagnosi, the therapeutic data, The postoperative suite has been studied. The informed consent of the patients was respected for the realization of this work.

\section{Results}

In 14 years 40 cases of cholelithiasis were collated s in service, with an average of 2.8 cases per year. She represented $0.15 \%$ of the entire consultation for the period of the study and $0.37 \%$ surgery during the same period. Females accounted for $70 \%(n=28)$ of cases with a gender ratio of 2.3 for women. The mean age of patients was 60 years with a standard deviation of 11.44 and extremes of 32 years at 78 years. In the study $62.5 \%$ of patients $(n=25)$ were referred by a specialist physician.

The clinical signs found in the study are reported in Table 1.

In $35 \%$ of patients $(n=14)$ choledochal lithiasis was associated with vesicular lithiasis. Ultrasound was performed in all patients $(n=40)$ and demonstrated lithiasis associated with primary biliary dilatation. Laboratory tests highlighted a cholestasis syndrome in 8 patients 20\%. Hyperleukocytosis was found in $5 \%$ of patients $(n=2)$. The risk factors found are reported in Table 2.

Table 1. Clinical signs found.

\begin{tabular}{ccc}
\hline Clinical signs & Effective & Percentage \\
\hline Triad of Charcot & 40 & 100 \\
Pruritus & 38 & 95 \\
Discolored urine dark feces & 40 & 100 \\
vomiting & 38 & 95 \\
Right hypochondrial defense & 8 & 20 \\
\hline
\end{tabular}

Table 2. Risk factors.

\begin{tabular}{ccc}
\hline Risk factors & Effective & Percentage \\
\hline Age $>$ to 40 years & 37 & 92.5 \\
Female & 28 & 70 \\
multiparity & 26 & 65 \\
Obesity & 22 & 55 \\
Family history & 8 & 20 \\
Sickle Cell & 4 & 10 \\
\hline
\end{tabular}


Table 3. Seat of the lithiasis and associated lesion.

\begin{tabular}{ccc}
\hline seat & Effective & percentage \\
\hline The low common bile & 30 & 75 \\
The bile duct & 10 & 25 \\
Associated vesicular lithiasis & 3 & 7.5 \\
\hline
\end{tabular}

The surgical procedure: The site of choledochal lithiasis and associated lesions are reported in Table 3.

The surgical procedure consisting of a cholecystectomy associated with a longitudinal cholodocotomy with extraction of the computation and establishment of a kheroside drain in the common bile duct in 39 patients (97.5\%) and a transcystic drain in a patient (2.5\%). Verification of the permeability of the bile was performed. Cholangiography was performed 3 days postoperative in all patients and not objectified residual calculation, but it revealed a case of bile leakage $2.5 \%(n=1)$. No patients received intraoperative cholangiography because of a lack of technical facilities in our structure. The Kher drain was removed postoperatively in 39 patients, or $99 \%$ of cases. The morbidity was marked by a case of biliary fistula is $2.5 \%(\mathrm{n}=1)$ and a case of abscess of the wall is $2.5 \%$ of cases. The mortality was $5 \%(=2)$, and the follow-up was simple in $90 \%$ of cases.

\section{Discussion}

In Mali the actual frequency of cholelithiasis is not known. The frequency observed in the western series varies between $10 \%-15 \%$ of the population among which 5\% - 15\% suffer from a lithiasis of the main gallstone (CBD) [10]. Surgery of the $\mathrm{CBD}$ represented in our study $2.8 \%$ of all surgery for gallstones, this frequency has been reported in men by studies carried out in Niger and Burkina [5] [6]. The prevalence and incidence of cholelithiasis increase with age. The average age of 60 years of our series does not differ from those of the Ivorian and French series [10]. Cholelithiasis is deemed to 2 to 3 times common in women than in men both in Africa and in the West [11]. This higher frequency in women is explained by the role of female sex hormones, contraception and estrogen therapie [12]. The sex ratio was 0.4 in our series against 3 in the study of Keita [7]. The febrile painful jaundice is observed in $50 \%$ of cases and achieves the choledochal syndrome which combines in less than 24 hours to 48 hours in the order: pain of the right hypochondrium, fever and jaundice. This triad known as the Charcot triad is one of the key elements in the clinical diagnosis of choledochal lithiasis. It was observed in $33 \%$ of cases in the series reported by Tham [13] against $100 \%$ in our series, this difference is explained by the fact that in our series the patients consulted late or all the clinical signs were already present. Ultrasound hepatobiliary was the morphological examination performed in all the patients of our series is $100 \%$ of cases. In the series of Tham [13] its percentage of realization was also $100 \%$ and made it possible to highlight in $60 \%$ of cases the lithiasis against $100 \%$ in our series. The performance of ultrasound in the diagnosis of CBD li- 
thiasis remains difficult to assess. Sensitivity figures reported in the literature range from 15 to $75 \%$. The examination conditions and the type of calculation are determining elements. Some authors [13] [14] have consistently asked the abdominal computed tomography (CT) in $71 \%-76 \%$ of cases in our study CT was requested when the result of an ultrasound was not contributory. In most series, biological tests have shown a cholestasis syndrome that varies between $20 \%$ and $30 \%$ [13] [14]. In our study, cholestasis syndrome was observed in 8 patients (20\%) and leukocytosis observed in 2 cases (20\%). Laparoscopy and sphincterotomy oscopique are the standard treatment of stones in the CBD in the West, these surgical approaches have many advantages over conventional surgery, they are not feasible in Mali for lack of technical facilities. This is why all the patients of our series were operated by laparotomy is $100 \%$ of cases, the median incision was the most used in our series, in the series reported by Keita [7] the right subcostal incision was the most performed, $80.7 \%$ of cases. The choice of the type of incision depends on the preference of the surgeon. Some authors believe that the right subcostal incision gives easy access to the bile ducts. The surgical procedure performed in our study was associated with cholecystectomy longitudinal cholodochotomie with stone extraction. External biliary drainage was performed in all patients either by a Kher drain 39 cases (97.5\%) or a trans cystic drain 1 case (2.5\%) against respectively $66 \%$ and $34 \%$ in the study conducted by N. Houes [14]. Cholangiography intraoperative was not performed in our patients by lack of technical support. However, if the technical conditions allow it, intraoperative cholangiography must be systematic to verify the patency of the bile duct and the existence of residual stones. It was performed in all patients in the study reported by N. Houes [14] or $100 \%$ of cases. An under-hepatic drain was placed in all of our patients 50 cases (100\%) against $23 \%$ of cases reported by Traoré S. S. [6]. This drainage is intended to collect a possible bile leak or bleeding. A cholangiogram was performed in all our patients 3 days after the operation through the Kher drain or cystic drain. It did not objectify residual calculation but 1 case (2.5\%) of biliary leak was found it did not require recovery. The Kher drain was removed at 8 days post operative. The overall morbidity was $10 \%$ in our series against $25 \%$ observed in the Keita series [7]. The morbidity observed in our series was marked by 1 case $(2.5 \%)$ of biliary fistula and 1 case $(2.5 \%)$ of wall abscess. The suites were simple in $90 \%$ of the cases.

\section{Conclusion}

The cholelithiasis is a potentially serious pathology, laparoscopy and interventional endoscopy replaced laparotomy in the West, however, laparotomy remains the first way in Mali. Morbidity can be reduced by the use of the endoscopic and laparoscopic approach.

\section{Conflicts of Interest}

The authors declare no conflicts of interest regarding the publication of this 
paper.

\section{References}

[1] Spost, S.J. (2000) Benigne Erkrankungen de Gallenblase und der Gallenwege. de Chirurg, 71, 1530-1551. https://doi.org/10.1007/s001040051257

[2] Takongmo, S., Gagnignil, L. and Malonga, E. (1991) La lithiase biliaire au CHU de Yaoundé à propos de 46 observations. Medecine d' Afrique Noire, 144, 36-39.

[3] Regent, D., Laurent, V., Meyer, B.L. and Lefevre, B.L. (2006) La douleur biliaire comment la connaitre? Comment l'explorer? Journal de Radiologie, 87, 413-429. https://doi.org/10.1016/S0221-0363(06)74024-0

[4] Salembier, Y. (1998) La Lithiase Biliaire Traitement Chirurgical. Medsi/McGraw-Hill, Paris, 123.

[5] Sani, R., Illo, R., Boukari Baoua, M. and Harouna, Y. (2007) Evaluation du traitement chirurgical de la lithiase biliaire à l'hopital national de Namey, revue de 136 observations. Medecine d Afrique Noire, 54, 104-109.

[6] Traoré, S.S., Zidan, M., Bonkoungou, G.P., Kafando, R. and Hakimi, G. (2009) Lithiase de la voie biliaire principale au CHU de Yalgado Ouedrago à propos de 41. Médecine d Afrique Noire, 56, 104-109.

[7] Keita, S., Koumaré, S., Soumaré, L. and Sacko, O. (2018) Lithiase de la voie biliaire principale chez les militaires dans les CHU de Bamako. Journal Africain de Chirurgie Digestive, 18, 2338-2313.

[8] Montariol,T., Msika, S., Charmier, A., Rey, C., Bataille, N., Hay, J.M., et al. (1998) Diagnosis of Asymptomatic Common Bile Duct Stones: Preoperative Endoscopie Ultrasonographiy versus Intraoperative Cholangiography: A Multicenter, Prospective Controlled Study. Surgery, 124, 6-13. https://doi.org/10.1016/S0039-6060(98)70068-6

[9] Moreaux, J. (1990) Traitement chirurgical de la lithiase de la voie principale. Ses resultats et son évolution dans une série de 707 cas. De Chirurgie, 116, 262-267.

[10] Koffi, E., Yenon, K., Ehua, S., Coulibaly, A., Kouassi, J.C. and Kanga, M. (1999) La lithiase de la voie biliaire principale en milieu ivoirien. Medecine $d$ Afrique Noire, 46, 114-118.

[11] Owono, P., Mingoutaud, L., Ivala, L., Nguema, M.V., Ngabou, U. and Nzenze, J.R. (2008) Cholecystectomie par laparoscopie. Expérience du CHU de Libreville à propos de 25 cas. Médecine d' Afrique Noire, 55, 86-29.

[12] Ellinger, S. (1986) Physiologie, épidémiologie, et histoire naturelle de la lithiase biliaire. Encyclo-Med. Chir(Paris France), foie-pancréas: 7047A-9, 10 p.

[13] Tham, O., Touré, A.O., Seck, M., Gueye, M.L., Cissé, M. and Bricha, M. (2O16) Lithiase des voies biliaires principales épidémiologiques, diagnostiques et thérapeutiques. Journal Africain d Hépato-Gastroentérologie, 10, 194-198. https://doi.org/10.1007/s12157-016-0680-6

[14] Haoues, N., Zaafouri, A., Fendri, S., Mrad, S., Noomen, R., Bouhafa, A. and Mamma, A. (2014) Résultats du traitement laparoscopique de la lithiase de la voie principale, à propos d'une série de 50. Journal Africain d' Hépato-Gastroentérologie, 8, 119-124. 